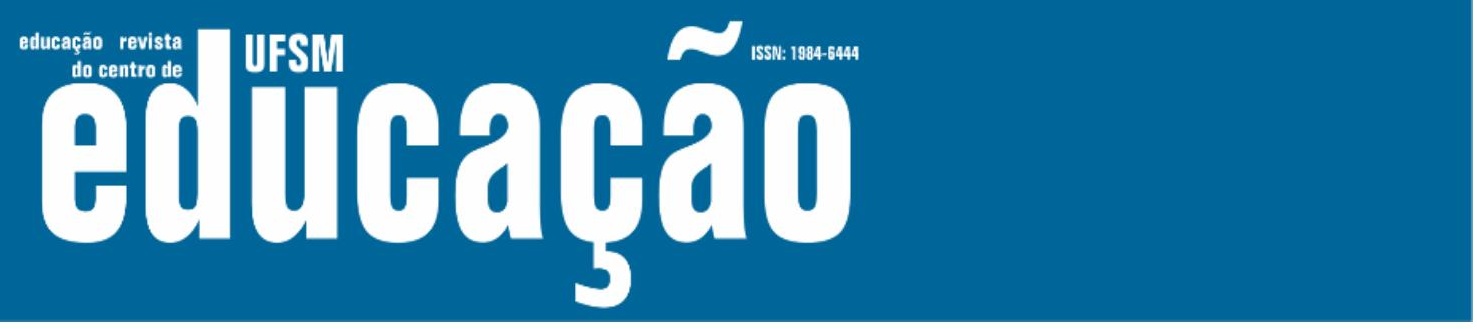

ISSN: 1984-6444 | http://dx.doi.org/10.5902/1984644433096

\title{
A Importância do Pensamento Crítico em Inovações Curriculares: interface com a educação sexual emancipatória
}

The importance of critical thinking in curricular innovations: interface with emancipatory sexual education

\author{
Yalin Brizola Yared \\ Professora doutora na Universidade do Sul de Santa Catarina, Florianópolis, Santa Catarina, Brasil. \\ yalinbio@gmail.com - https://orcid.org/0000-0001-8773-9358
}

Sonia Maria Martins de Melo

Professora doutora na Universidade do Estado de Santa Catarina, Florianópolis, Santa Catarina, Brasil. soniademelo@gmail.com - http://orcid.org/0000-0003-1089-3845

Rui Marques Vieira

Professor doutor na Universidade de Aveiro, Portugal.

rvieira@ua.pt - https://orcid.org/0000-0003-0610-6896

Recebido em 14 de junho de 2018

Aprovado em 17 de março de 2020

Publicado em 13 de maio de 2020

\section{RESUMO}

A partir de uma pesquisa de doutoramento no campo da Educação em interface com a sexualidade, o presente artigo discorre sobre a importância da promoção do Pensamento Crítico (PC) em mudanças paradigmáticas curriculares no ensino superior. O lócus do estudo foi um Curso de Graduação em Medicina organizado em currículo integrado, orientado por competências, com quadro docente interdisciplinar e multiprofissional, e desenvolvido por metodologias ativas. Objetivamos, neste ensaio, problematizar o desenvolvimento do PC como elemento substancial na materialização de uma proposta curricular que visa uma transformação paradigmática educacional. Norteado pelo paradigma do materialismo histórico dialético, o ensaio configura-se como um estudo de caso que utiliza o método dialético para análise da realidade. Os instrumentos de coleta compreenderam o uso de questionário e, posteriormente, a entrevista semiestruturada áudio gravada. Para análise, foi utilizada a análise de conteúdo, com complementos da análise textual discursiva. Como resultado, registrou-se que o desenvolvimento intencional do PC é fundamental para a busca de uma transformação paradigmática educacional efetiva. Embora hoje sejam defendidos e divulgados vários elementos inovadores no processo de ensino e de aprendizagem, muitos docentes do ensino superior continuam agindo amparados no paradigma convencional acriticamente. Isso sugere que as práticas não promovem naturalmente o PC. 


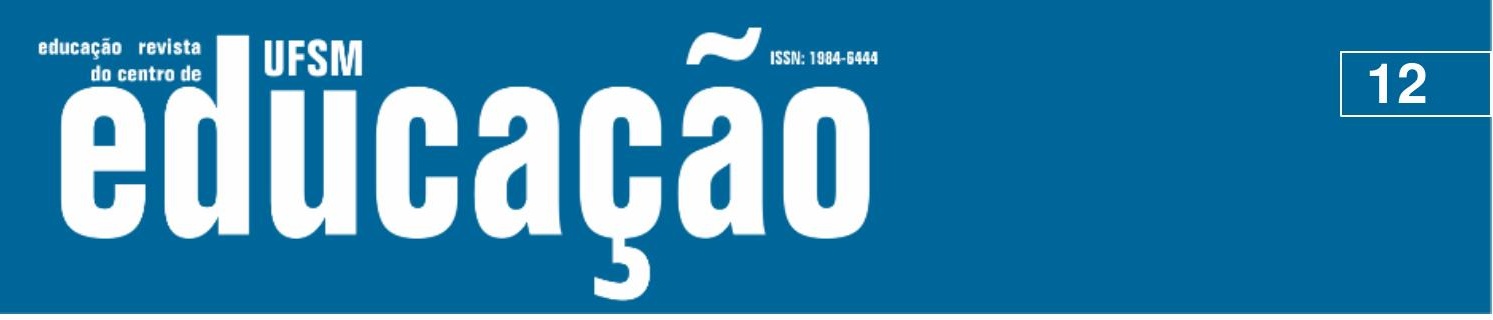

ISSN: 1984-6444 | http://dx.doi.org/10.5902/1984644433096

sentem preparados e, consequentemente, não conseguem conduzir discussões, ou as consideram insatisfatórias. Vejamos:

\begin{abstract}
"Eu confesso que pra mim é uma dificuldade bastante grande...porque a gente não sabe como lidar, como conduzir. (Átropos, Não-med.)"

"Foi bem pontual assim...longe do que eu acho que deveria ser abordado. Mas também não pensei de que maneira eu poderia abordar isso. (Hades, Med.)"

"Eles [estudantes] sabem lidar mais com essa mudança de...né? (...) Eles sabem lidar muito bem com isso. A gente que não sabe. (Cloto, Não-med.)"

"Os professores estão bem atrapalhados e não sabem como trabalhar. (Panacéia, Med.)"

"A gente vê relatos de professores que não conseguem saber qual é o jeito melhor de lidar...a gente tem relatos...a gente ouve conversas né...até mesmo de situações de preconceitos, sabe. Então a gente acaba não estando preparados. Na realidade assim...ninguém tá preparado. (...) Porque quando é tudo normal, beleza. Tudo normal. E quando não é? (Aglaea, Med.)"
\end{abstract}

Entendemos que o desconhecimento e as dúvidas promovem inseguranças, intimidam e limitam o diálogo. Ressaltamos a importância de se promover formações específicas nessa área do conhecimento, pois poderão contribuir significativamente para a reflexão crítica de mitos, crenças e tabus, além da superação de currículos ocultos (FIGUEIRÓ, 2006, 2018; CARVALHO et al, 2012; YARED, MELO E VIEIRA, 2015; YARED, VIEIRA E MELO, 2015). Assim, os docentes justificam que, por não se sentirem preparados, os debates acabam sendo evitados, conforme podemos verificar a seguir:

\footnotetext{
"E quando a gente não sabe o que fazer com essas questões...geralmente vai pra baixo do tapete né. Não mexe...porque se eu não sei trabalhar com isso...não vou trazer em pauta. Então...acaba que a gente sempre joga pra escanteio. Deixa de lado...deixa à margem das discussões pra não ter que precisar mexer. (Átropos, Não-med.)"

"Então...muitas vezes acaba passando batido várias coisas né. E...via de regra...a sexualidade é uma coisa que eu...ao menos que eu veja que o paciente tá me dando essa oportunidade de explorar...eu acabo não explorando. (Hades, Med.)"
}

Os/as docentes entrevistados/as relataram também que consideram a temática muito desafiante e, inclusive, de abordagem complexa: 


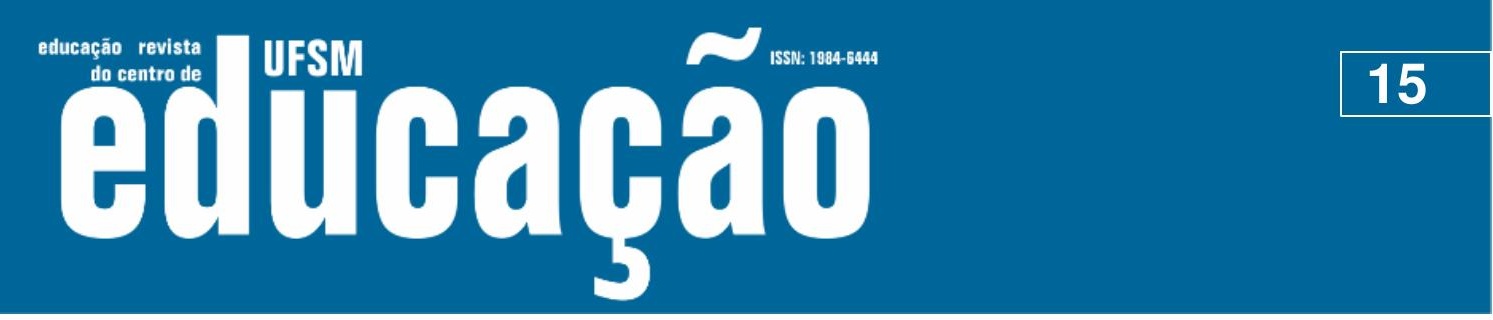

ISSN: 1984-6444 | http://dx.doi.org/10.5902/1984644433096

"Eu acho que tá lá só pra constar...É minha opinião até o momento. Eu posso estar enganada...to falando uma opinião totalmente pessoal. Não de abordagem...não fui falar com nenhum professor do $3^{\circ}$ ano pra perguntar isso...não fiz pesquisa com os alunos no final do $3^{\circ}$ ano pra saber...tu me entendeu? Eu quero dizer assim...é só o que eu to vendo...quando eles chegam aqui [anos seguintes]...tu vê se tem alguma habilitação, não tem. É isso que eu vejo. E daí não sei te dizer. Nunca trabalhei com o $3^{\circ}$ ano...então é só numa reunião pontual lá, de colegiado...então eu não me sinto habilitada a realmente expressar uma opinião a respeito. Eu posso te falar sobre os alunos que chegam [aqui] e que a abordagem deles em relação a isso...ela é muito pequena. (Deméter, Med.)"

"Eu acho que é uma coisa bastante...que vai ser bastante benéfico pra formação dos alunos...dos nossos próximos...vão ser nossos colegas. Talvez eles estejam mais preparados pra lidar com situações como essas. Tanto na vida profissional como na vida pessoal. Só que claro...isso depende de formação de quem tá formando eles. (Aglaea, Med.)"

Mais especificamente, sobre o $3^{\circ}$ ano do curso, os/as docentes ressaltaram não perceberem transformações nos estudantes após vivenciarem essa Unidade Educacional. Esta observação foi apontada tanto por docentes de $1^{\circ}$ e e/ou $2^{\circ}$ ano inclusive do $3^{\circ}$ ano, como por docentes do $4^{\circ}, 5^{\circ}$ e/ou $6^{\circ}$ ano. E, aliás, por docentes que trabalham tanto em anos iniciais como em anos finais do curso, concomitantemente. Deméter é assertiva ao registrar que não há diferença no comportamento e conhecimento dos estudantes que chegam ao final do curso, sendo que, contraditoriamente, também é docente de estudantes dos anos iniciais. Artemis também relata que não percebe diferença. Ao contrário, Aglaea acredita que isso pode ser benéfico, e que os estudantes podem, inclusive, estar mais preparados futuramente, mas aponta que o sucesso desse processo dependerá da formação ofertada ao formador. Aglaea é docente tanto de turmas iniciais como intermediárias, e durante sua própria entrevista, num processo de antítese, reelabora seu entendimento, conforme podemos observar a seguir:

\footnotetext{
"Por exemplo...tenho alunos do [antes do $3^{\circ}$ ano] e do [depois do $3^{\circ}$ ano] e percebo que a dificuldade é a mesma. Tanto pros alunos [antes]...claro, com as devidas correções do ano...tanto dos que já evoluíram, mas...os alunos do [depois] ainda tem aquela ressalva assim de... 'bha, peguei um paciente que é uma queixa que tá relacionada...vou ter que fazer perguntas relacionadas à sexualidade' ....aí eles já ficam meio nervosos. (Aglaea, Med.)"

"Ah...não...não acho que interfere no meu...método assim. Até porque eu não percebi diferença. Nem nesses alunos do [início] que ainda não tiveram contato [com o $3^{\circ}$ ano], nem dos que estão [após o $3^{\circ}$ ano]. (Artemis, Med.)"
} 


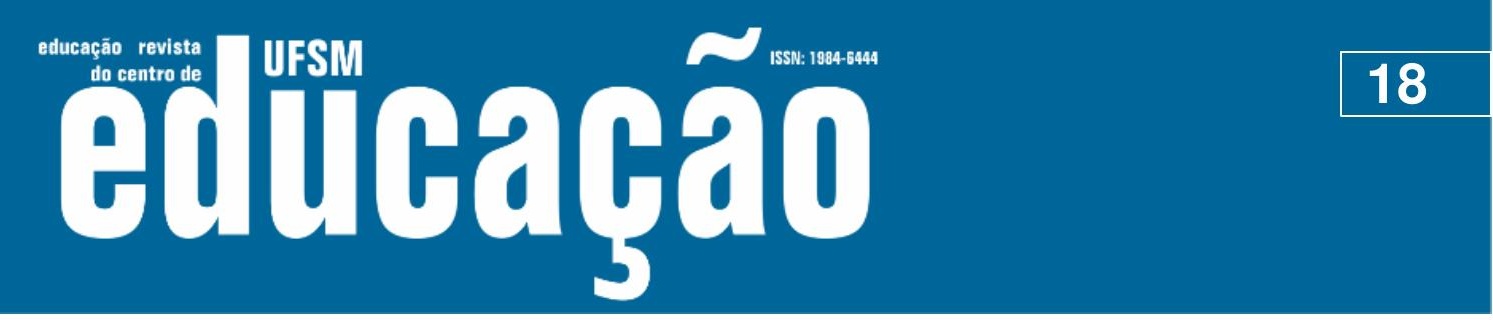

ISSN: 1984-6444 | http://dx.doi.org/10.5902/1984644433096

\begin{abstract}
"Aí começava assim...'nós precisamos que tu venha dar uma palestra'...(Deméter, Med.)"

"Eu pensei em fazer a pós-graduação de educação sexual porque utiliza muito na área que eu trabalho. (...) $\mathrm{E}$ há uma necessidade assim...impressionante. De informação. Principalmente assim...a gente teria que abordar melhor em escola...mas abordar, não é ir lá fazer palestrinha...é abordar com os professores. Sabe...a gente tem que trabalhar com quem tá todo dia com eles. Não é? Eu chego lá...uma pessoa pontualmente...uma vez na vida deles...entende? E quem tá todo dia com eles...essas pessoas que tem que habilitar. E a gente divulgar mais isso...como é que vou dizer...trabalhar mais com as famílias...trabalhar mais com o médico que trabalha na unidade de saúde. (Deméter, Med.)"
\end{abstract}

Registramos a análise crítica apresentada por Deméter sobre a realidade em que se inseria. Sua preocupação com as ações pontuais também vêm ao encontro do que afirmam Melo et al. (2011), Yared (2011), Carvalho et al. (2012) e Yared, Vieira e Melo (2015) sobre a importância de se efetivarem programas e/ou projetos sistematizados, em médio/longo prazo, para a abordagem específica do tema. Porém, para além da constatação, em vez de se adaptar, optou por "mudar ou melhorar as condições objetivas através de [sua] intervenção no mundo" (FREIRE, 2000, p. 41). Decidiu, então, organizar e promover formação docente. Ao explicar como funcionavam os cursos, demonstrou interesse e prioridade pelo diálogo e interação com os professores.

“(...) daí que me dei conta...não adianta eu tá...é professor que tá faltando. Aí eu fiz capacitação para professores trabalharem com adolescentes...rodei o Estado dando curso. (Deméter, Med.)"

"[duração dos cursos] Depende da necessidade. Por exemplo, tinha escolas...a gente fez um curso, por exemplo, de cinco dias. Era uma semana. Daí dava mais tempo...eu posso fazer dinâmica de grupo...tu agrega mais... Por exemplo, tinha locais que eram $8 \mathrm{~h}$. Só. $4 \mathrm{~h}$ de manhã e $4 \mathrm{~h}$ de tarde. Digamos assim, era variado...mas menos...eu não trabalho com nenhuma escola menos que 8h. Nunca fui. Porque senão eu vou chegar lá...eu vou conseguir passar uma falinha que daí não vai dar pra gente interagir...entender...e cada um pode pegar só um ganchinho que eu falei e achar que aquilo é uma verdade. Eu não acho produtivo. Claro, tinha escola que eu já tinha feito cursos de capacitação de todos os professores...daí às vezes eles me pediam pontualmente... 'nós estamos com tal situação, dificuldades assim, tu poderia fazer?'... Posso. Por que? Porque os professores já estavam habilitados a receber a minha fala ali e não ia sair distorção. Entende? (Deméter, Med.)"

Percebemos como fundamental o caminho da dialogicidade e da comunicação. Entendemos que, para vivenciar o humanismo verdadeiro, é necessário vivenciar o diálogo, e que pensar de forma crítica pode proporcionar "aos cidadãos as ferramentas 


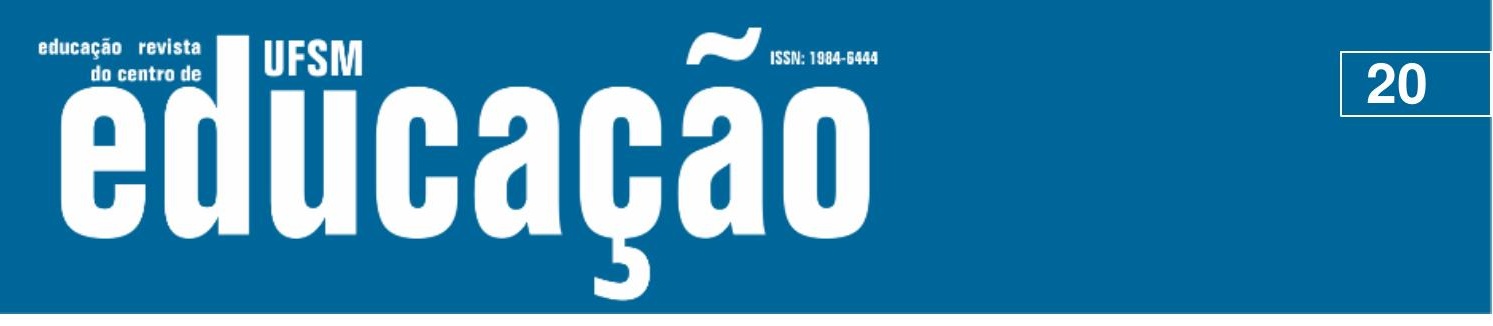

ISSN: 1984-6444 | http://dx.doi.org/10.5902/1984644433096

O objetivo específico seguinte também pode estar em busca durante as ações de Deméter, uma vez que visa "identificar, conhecer, analisar e propor alternativas de ação apropriadas à realidade vivida, através da leitura e da análise do cotidiano, tendo este como o verdadeiro espaço e objeto de intervenção profissional" (PPC, 2012, p. 13). Vejamos:

"Eu mandei eles assim... 'vamos mapear aí...tem a associação de bairro...quem é o presidente...o que eles precisam...onde é a creche...Vamos lá...vamos lá...mas eu tenho que deixar eles protagonistas. Vão lá...falem com a diretora...quando que a gente pode fazer uma visita...pra creche e na escola. Me descubram que escolas que tem aqui...vão lá... (...) A unidade me sedia pra trabalhar. Eu não era médica da unidade. Eu não era contratada pela unidade. Eu ia lá só pra trabalhar com os alunos. Então, a unidade me fazia a gentileza de ceder os pacientes pra gente fazer o acompanhamento. (Deméter, Med.)"

Registramos que Deméter orientava seus estudantes no desenvolvimento de um projeto de ação na comunidade e os acompanhava. Ele descreve:

“Daí na escola....a mesma coisa...os professores queriam que se falasse
primeiro sobre sexualidade... Daí eu disse... 'eu não sou bombeira'...uma
engravida e eles lembram que tem que fazer isso. Geralmente é assim. Daí
eu disse... 'eu não sou bombeira, me nego a fazer isso, eu não faço isso'... E
eu perco, vou te dizer, até financeiramente de fazer palestra, porque eu não
faço isso. E é bem assim...tanto escola particular quanto pública. Uma
engravida ou tem uma situação de que descobrem de violência...aí todo
mundo quer uma palestra. Achando que a palestra vai resolver. Não é assim!
Eu não faço. Mas de jeito nenhum. Daí eles também pediram [na escola do
bairro] e eu disse... 'não, vão lá, falem com os professores, qual é a
dificuldade, vejam os professores que gostariam de ser habilitados'... aí a
gente trabalhou com os professores...mas eu fiz os alunos fazerem um
projeto...eu orientava. Aí não fui eu lá fazer...entendeu? A gente faz que nem
o método PBL...a gente fez tipo um seminário.... Os alunos protagonizaram
isso e eu fazia, digamos assim, o arremate. (...) Porque o meu objetivo era
fazer os alunos se antenarem pra isso. Eu estava trabalhando na verdade
como professora dos meus alunos, entendeu? Claro que...vendo o perfil da
comunidade e daqueles alunos...que tinha essa necessidade...os professores
também....mas eu não podia tirar do meu foco que lá eu era professora. (...)
Daí foi bom, porque os meus alunos foram pesquisar sobre sexualidade,
foram atrás. (Deméter, Med.)"

O relato de Deméter aponta para a importância do aspecto científico da sexualidade e para a constituição do sujeito ativo, crítico e autônomo, tanto de si como de seus estudantes. Deméter denuncia com segurança "não sou bombeira", portanto "me nego a fazer isso", recusando-se a proferir palestras aos estudantes da escola chamando atenção para a importância de processos educativos sistemáticos e 


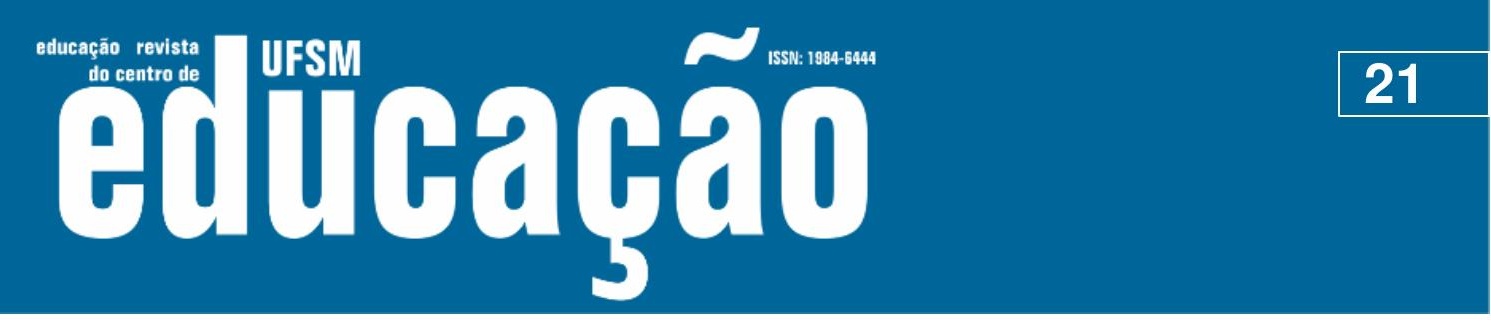

ISSN: 1984-6444 | http://dx.doi.org/10.5902/1984644433096

contínuos, não pontuais. Nesse sentido, num processo de educação sexual ressignificado por ela e vivido juntamente com seus estudantes, vão à escola como profissionais da área, demonstrando significativos sinais de emancipação e ressaltando a importância da abordagem com responsabilidade, comprometimento, reflexão crítica e estudo.

Deméter apresenta-se como um dos docentes que trabalha com turmas antes e depois do $3^{\circ}$ ano. Todavia, mesmo diante de todas as ações desenvolvidas junto às UBS, relatou que não observava diferença nos estudantes ao final do curso, pois não apresentavam preparo para trabalhar com questões de sexualidade. Foi quando decidiu, diante de mais este incômodo e por conta própria, desenvolver um projetopiloto, criando um ambulatório de adolescência que desenvolve trabalhos num hospital da cidade, duas vezes por semana, com estudantes sextanistas.

“Então...o fato de eles chegaram no $6^{\circ}$ ano...a gente começa a ver aonde que
ficaram as fraquezas. Também as fortalezas. Isso me permite avaliar.
Geralmente...quando eles entram no ambulatório eu faço um pré-teste. Daí
ontem a gente foi corrigir o pré-teste que eles fizeram. A fala de todos eles
era assim... 'ai, professora, ainda bem que veio isso aqui'... na verdade, no
pré-teste (...) eu estava avaliando só desenvolvimento físico da puberdade.
Porque eu precisava saber...é pouco tempo que eu tenho e eles precisam
sair com uma noção. Aí eles... 'bha professora, se a gente não visse isso
agora a gente ia sair sem ter essa mínima noção e olha como eu preciso isso'.
Então, a gente atende uma criança...eu chego e pergunto... a criança tem
dois meses, por exemplo... 'mãe, a senhora quer ter mais filho?'... 'não..... 'e
daí o que que a senhora tá fazendo pra não engravidar?'... Boa parte delas
não tá usando nada. Eu digo... 'mãe, a não ser que a senhora não transe, a
senhora corre o risco de engravidar, mesmo estando amamentando
exclusivamente'. Então eu digo pros meus alunos... 'ó, na alta, cartinha que
tem que ir especificamente...de anticoncepção ou vocês já vão
prescrever...se já se acham aptos pra avaliar'. Aí a maioria deles... 'mas isso
não é...eu não tenho que mandá-la pra unidade? Isso não é do médico de
lá??. Eu digo...vocês podem achar que não. Eu não acho. Se a mulher
engravida logo em seguida e ela tem condições...então o problema não é
do...o problema é nosso! É do pediatra. No caso, eu estava ali como pediatra.
É do pediatra. Então assim...não tem a noção que isso faz parte de abordar.
Não tem essa noção. Isso em todos. É muito pouco abordado. (Deméter,
Med.)"

Assim como a maioria dos/as docentes participantes das entrevistas, Deméter apresenta bastante inquietude - "o problema é nosso" - frente à sexualidade, porém, buscando romper sua própria zona de conforto, criou um ambulatório. A vivência em um currículo integrado deu oportunidade a Deméter de colocar em prática seus 


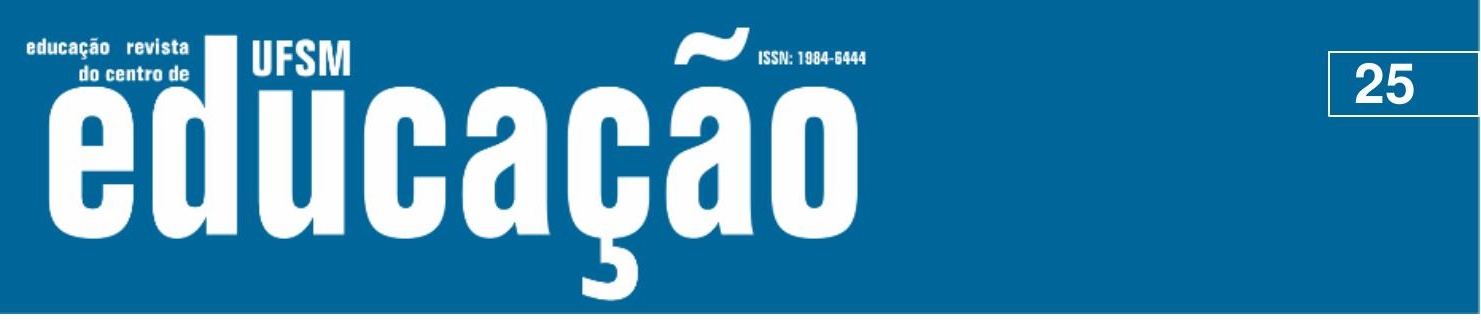

ISSN: 1984-6444 | http://dx.doi.org/10.5902/1984644433096

entendível quando nós, profissionais da Educação e da Saúde, não nos vemos como sujeitos dos processos que vivemos, pois somos frutos de processos formativos sócio historicamente que transcorreram (e transcorrem) na contramão da emancipação, ou seja, na contramão de ações libertadoras e críticas. Assim, muitas vezes assumimos a posição de expectadores e não de protagonistas quando esperamos por outrem a solução dos desafios do nosso cotidiano. Essas recaídas ao modelo tradicional são contradições da vivência pedagógica que representaram uma mudança paradigmática ainda não sedimentada, uma vez que colocam a responsabilidade da mudança que desejam para outrem e não se veem como parte dessa mudança.

Ressaltamos que as contradições identificadas representam, no método dialético, que o processo está em movimento, ou seja, não está estático. A contradição é a essência da dialética, entendida não como um aspecto negativo nas ações dos/as docentes, mas como sinal de esperança. Porque é sinal de que o curso está em movimento, em transição, e, consequentemente, o que-fazer docente também, conforme seu nível de reflexão. As contradições representam um processo de saúde pedagógica, considerando que suas ausências nos revelariam um curso cristalizado e determinado, paralisado numa verdade sem movimento. Em uma proposta curricular inovadora, as contradições que brotam da vivência são próprias de uma proposta que se propõe revolucionária, possivelmente desafiante, visto que muitos de nós, ainda formados num modelo tradicional educativo, percorreremos um laborioso caminho à emancipação e promoção de uma educação verdadeiramente libertadora.

Por fim, a formação continuada e permanente apresenta-se como um local privilegiado para promover intencionalmente o pensamento crítico, a práxis pedagógica, estimular e fortalecer a autonomia docente, especialmente em processos de educação sexual emancipatória. Integrar intencionalmente o desenvolvimento do PC na formação docente pode potencializar a formação de sujeitos racionais e autônomos, com capacidade de pensar por si mesmos, não sendo dependentes de outrem. Promover a construção coletiva de uma reflexão crítica explicitamente consciente e racional dos/as docentes de Medicina sobre suas vivências e práticas didático-pedagógicas pode potencializar, portanto, a transformação paradigmática educacional almejada pelo curso. 


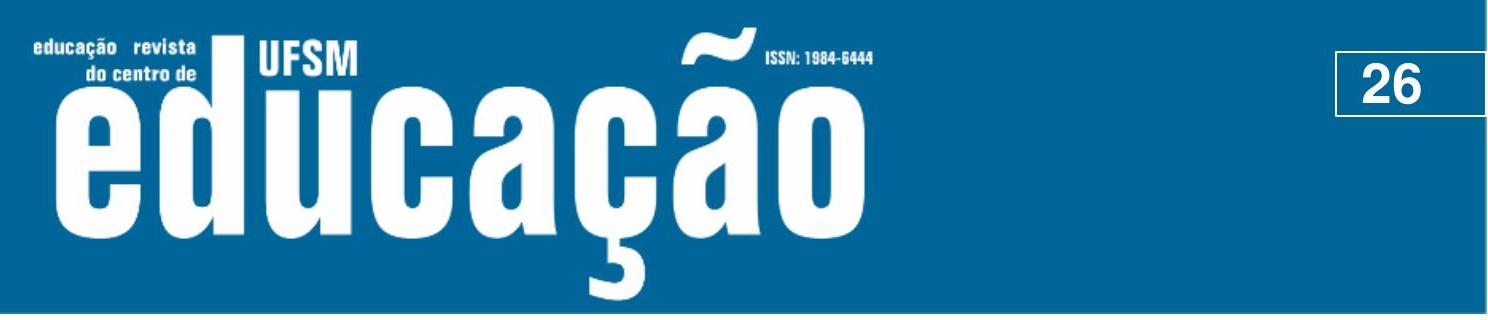

ISSN: 1984-6444 | http://dx.doi.org/10.5902/1984644433096

\section{Referências}

BARDIN, Laurence. Análise de conteúdo. Tradução: Luís Antero Reto e Augusto Pinheiro. 4. ed. Lisboa/Portugal: Edições 70, Lda. 2014.

BRASIL. Conselho Nacional de Educação. Câmara de Educação Superior. Diretrizes curriculares nacionais do curso de graduação em Medicina. Resolução nำ 4, de 07/11/2001. Diário Oficial da União, 09/11/2001, Brasília, Seção 1, p. 38, 2001.

BRASIL. Conselho Nacional de Educação. Câmara de Educação Superior. Diretrizes curriculares nacionais do curso de graduação em Medicina. Resolução nํ 3, de 20/06/2014. Diário Oficial da União, 23/06/2014, Brasília, Seção 1, pp. 8-11, 2014.

CABRAL, Juçara Teresinha. A sexualidade no mundo ocidental. Campinas, São Paulo: Papirus, 1995.

CARVALHO, Gabriela Maria Dutra de; et al. Educação sexual: interfaces curriculares: caderno pedagógico. Florianópolis: UDESC/CEAD/UAB, 2012.

DECKER, Isabel Cristina Uarthe. A categoria emancipação em Paulo Freire e suas contribuições para um processo de educação sexual emancipatória. 2010. 200f. Dissertação (Mestrado em Educação) - Centro de Ciências Humanas e da EducaçãoFAED, Universidade do Estado de Santa Catarina-UDESC, Florianópolis, 2010.

ENNIS, Robert H. Critical thinking. Upper Saddle River, NJ: Prentice Hall. 1996.

ENNIS, Robert $\mathrm{H}$. The nature os critical thinking: an outline of critical thinking dispositions and abilites. This is a several-times-revised version of a presentation at the Sixth International Conference on Thinking at MIT, Cambridge, MA, July, 1994. Last revised May, 2011. Disponível em: http://faculty.education.illinois.edu/rhennis/documents/TheNatureofCriticalThinking_5 1711_000.pdf. Acesso em: 20 de jun. 2016.

FIGUEIRÓ, Mary Neide Damico. Formação de educadores sexuais: adiar não é mais possível. Campinas, SP: Mercado das Letras; Londrina, PR: Eduel, 2006.

FIGUEIRÓ, Mary Neide Damico. Educação sexual: saberes essenciais para quem educa. Curitiba: CRV, 2018.

FRANCO, Amanda; VIEIRA, Rui Marques; SAIZ, Carlos. O pensamento crítico: as mudanças necessárias no contexto universitário. In: Revista de Estudios e Investigación em Psicología y Educación, vol. extr., n. 07, 2017. DOI: https://doi.org/10.17979/reipe.2017.0.07.2233.

FREIRE, Paulo. Pedagogia da indignação. Cartas pedagógicas e outros escritos. São Paulo: UNESP, 2000.

FREIRE, Paulo. Pedagogia do oprimido. 29. ed. Rio de Janeiro, Paz e Terra, 2005. 


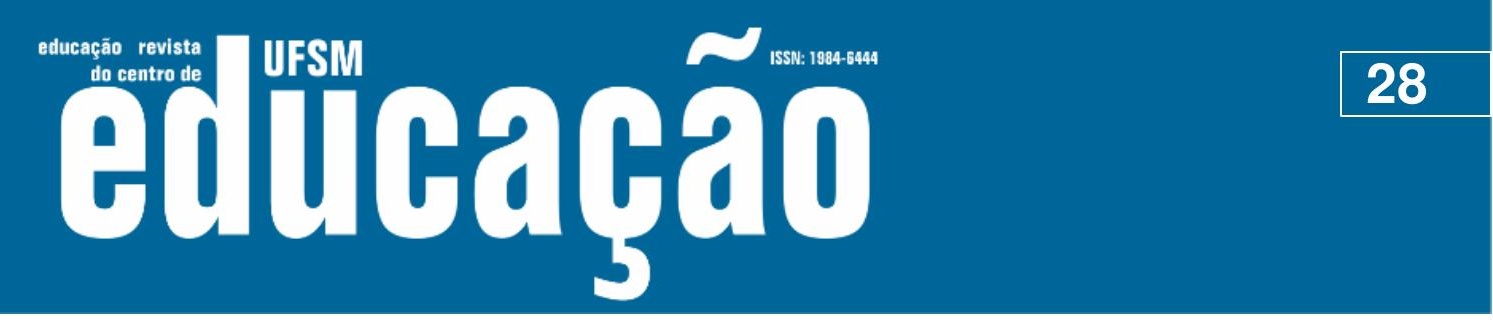

ISSN: 1984-6444 | http://dx.doi.org/10.5902/1984644433096

SILVA, Edna. A escola, a clínica e a sexualidade humana. In: Revista Perspectiva. Florianópolis, v. 16, n. 30, p. 115-142, jul./dez. 1998.

SILVA, Tomaz Tadeu da. Documentos de identidade: uma introdução às teorias do currículo. 3. ed. 1. Reimp, Belo Horizonte: Autêntica, 2005.

STAKE, Robert E. A arte da investigação com estudos de caso. 3. ed. Lisboa: Fundação Calouste Gulbenkian, 2012.

TENREIRO-VIEIRA, Celina. Perspectivas futuras de investigação e formação sobre pensamento crítico: potenciais convergências com as literacias Científica e Matemática. In: VIEIRA, Rui Marques; TENREIRO-VIEIRA, Celina; SÁ-CHAVES, Idália; MACHADO, Celeste. (Orgs.) Pensamento Crítico na Educação: perspectivas atuais no panorama internacional. Aveiro: UA Editora, 2014.

TENREIRO-VIEIRA, Celina; VIEIRA, Rui Marques. Promover o pensamento crítico dos alunos: propostas concretas para a sala de aula. Porto Editora, 2000.

TRIVIÑOS, Augusto Nibaldo Silva. Introdução à pesquisa em ciências sociais: a pesquisa qualitativa em educação. 1. ed. São Paulo: Atlas, 2012.

VIEIRA, Rui Marques; VIEIRA, Celina. Estratégias de ensino/aprendizagem: o questionamento promotor do pensamento crítico. Coleção: Horizontes pedagógicos, sob a direção de António Oliveira Cruz. Instituto Piaget: Lisboa, 2005.

VIEIRA, Rui Marques; TENREIRO-VIEIRA, Celina. Investigação sobre o pensamento crítico na educação: contributos para a didática das Ciências. In: R. M. Vieira, C. Tenreiro-Vieira, I. Sá-Chaves \& C. Machado (Orgs.) Pensamento Crítico na Educação: perspectivas atuais no panorama internacional (pp. X-y) Aveiro: UA Editora, 2014.

VIEIRA, Rui Marques; TENREIRO-VIEIRA, Celina; MARTINS, Isabel P. A educação em ciências com orientação CTS: atividades para o ensino básico. Areal, Editores. Porto, 2011.

WAS. Declaração dos Direitos Sexuais. 2014. Disponível em: http://www.worldsexology.org/wp- content/uploads/2013/08/DSR-Portugese.pdf. Acesso em: 13 de abr. 2015.

YARED, Yalin Brizola. A educação sexual na escola: Tensões e prazeres na prática pedagógica de professores de Ciências e Biologia. 2011. 140f. Dissertação (Mestrado) - Programa de Mestrado em Educação, Universidade do Planalto Catarinense, Lages, 2011.

YARED, Yalin Brizola. Do prescrito ao vivido: a compreensão de docentes sobre o processo de educação sexual em uma experiência de currículo integrado de um curso de Medicina. Tese (Doutorado) - Universidade do Estado de Santa Catarina, Centro de Ciências Humanas e da Educação, Programa de Pós-Graduação em Educação, Florianópolis, 2016. 
